\title{
NUMERICAL INVESTIGATION OF FLOW AND HEAT TRANSFER IN MICRO CHANNEL HEAT SINK SUBJECTED TO VARYING HEAT SPOT
}

\author{
Saravanan. ${ }^{1}$, C.K. Umesh ${ }^{2}$, Doddamani Hithaish ${ }^{3}$ \\ ${ }^{I}$ Assistant Professor, Department of Mechanical Engineering, BNMIT, Bangalore,(KA) India \\ ${ }^{2}$ Professor, Department of Mechanical Engineering, UVCE, Bangalore, (KA) India \\ ${ }^{3}$ PG student, Department of Mechanical Engineering, UVCE, Bangalore, (KA) India
}

\begin{abstract}
Micro-channel heat sinks are known as one of the effective cooling techniques because of its undeniable advantages of smaller physical dimensions and higher heat transfer efficiency. Since most of the electronic cooling systems deals with non-uniform heating, a numerical analysis was carried out for flow inside a micro channel of cross sectional area 489 $x 100 \mu \mathrm{m}$ and length of $2 \mathrm{~cm}$ with water as the working fluid.The work was carried out for varying heating position namely uniform, upstream, central, downstream and discrete heating of values $50 \mathrm{~W} / \mathrm{cm} 2$ and $70 \mathrm{~W} / \mathrm{cm} 2$. The thermal resistance, pumping power, heat transfer coefficient and surface temperature were studied for different heating condition under laminar regime. The entire work was carried out using Finite volume solver. It was observed that the hydrodynamic and thermal behaviour of micro channel heat sink with discrete heating position was better in comparison with other heating position.
\end{abstract}

Keywords: Micro channel, Uniform, upstream, Downstream, Central and Discrete

\section{NOMENCLATURE}

A

$\mathrm{P}$

$\mathrm{T}$

$\mathrm{u}, \mathrm{v}, \mathrm{w}$

$\mathrm{d}_{\mathrm{h}}$

$\mathrm{k}$

Re No

q

$\mathrm{h}$

W

$\mathrm{H}$

L

$\mathrm{Cp}$

Greek symbols

$\rho$

$\nabla$

$\mu$

Subscript

in Inlet

out outlet

max maximum

th thermal

c channel

s sink

h heating ****

Area $\mathrm{m}^{2}$

Perimeter

Temperature K

Velocity in $\mathrm{X}, \mathrm{Y}$ and $\mathrm{Z}$ direction

Hydraulic diameter

Thermal Conductivity

Heat flux W/cm ${ }^{2}$

Heat Transfer Coefficient

Width, $\mathrm{cm}$

Height, $\mathrm{cm}$

Length, $\mathrm{cm}$

Specific heat

Density

Del operator

Dynamic viscosity

\section{INTRODUCTION}

The design of next generation, giga-scale integrated circuits, requires effective cooling for reliable, long term operations. These devices may even experience catastrophic failure due to generation of very high heat flux (VHHF) transients. The VHHF transients originate from hot spots which may be difficult to localize at all times and will be difficult to handle using conventional cooling techniques. Micro-channel heatsinks have thus emerged as a promising cooling solution due to high heat transfer coefficient derived from a large surface area to volume ratio. The performance of these devices is directly related to the temperature; therefore it is a critical issue to maintain the electronic device at acceptable temperature levels. Hence the micro channel heat sink study is emphasized.The work on micro channel was first proposed by Tuckerman and pease [1] for electronic cooling .Weilin et al. [2], investigated pressure drop and heat transfer characteristics of a single-phase micro-channel heat sink for constant heat flux .Issam et al. [3], numerically studied the effect of Reynolds number and thermal conductivity of solid substrate on heat transfer process for a three dimensional micro channel heat sink. G. Hetsroni et al. [4] and Poh seng lee et al. [12], experimental and theoretical investigated heat transfer in micro channels for different geometries. R W knight et al. [5] performed analytical work on thermal resistance in terms of the number of channels, fins to channel thickness ratio, and showed significant reduction in thermal resistance. Gabriel Gamrat et al. [6] emphasized the effect of thermal entrance and coupled conduction/convection on heat transfer in micro 
channel. Zhao et al. [7] proposed porous medium model and fin approach to study heat transfer performance of heat sink analytically. A. Khan et al. [8] optimized micro channel heat sinks using entropy generation minimization method. Rathnasamy et al. [9] experimentally investigated heat transfer over laminar region using ethanol, methanol and ethanol-methanol mixture and developed a empirical correlation for nusselt number. Dorin lelea et al. [10] numerically studied the influence of the heating position on the thermal and hydrodynamic behaviour of heat sink. Ryu et al. [11] numerically investigated thermal performance of micro channel heat sinks and discussed the effect of the change in nusselt number for thermally fully developed flow and thermally non-developed flow.Kou et al. [13] optimized thermal performance of micro-channel heat sink by adjusting channel width and height. Riyu chein et.al [14] numerically investigated fluid flow and heat transfer in micro channel heat sink with various inlet and outlet configuration. J li et al. [15] presented numerical simulation of forced convection heat transfer in silicon based micro channel heat sink using three dimensional conjugate heat transfer model. From the literature review it is observed most of the work is investigated for hydraulic and thermal parameters for flow inside a micro channel for constant length and constant heat flux. However in realistic the heating length of electronic component is not equal to total length of micro channel and the total heat flux doesn't remain constant, consequently the thermal and hydraulic parameters depends upon heating length and heat flux. The scope of this paper is to study the hydraulic and thermal behavior for flow inside a micro channel for different heating position.

\section{PROBLEM DESCRIPTION}

A physical model of a micro channel embedded inside a conducting solid which is the same used in the investigation carried out by Dorin Lelea [10], is shown in Fig.2.1. Due to symmetry plane, half cross section of single channel is considered .Fig. 2.2 (a) shows the elemental volume of the micro channel heat sink used as the computational domain in this study. The dimension of present work is listed in table 2.1.Computation is carried out for different heating condition namely uniform, upstream, central, downstream and discrete heating as shown in figure 2.2 (b).

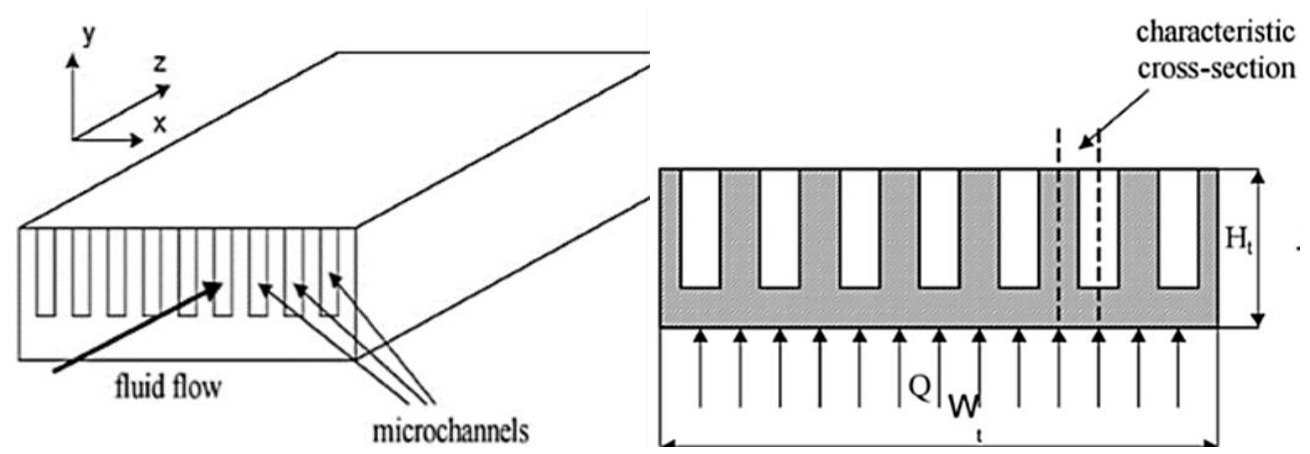

Fig-2.1: Arrangement of Three Dimensional Micro Channel Heat Sink [10]
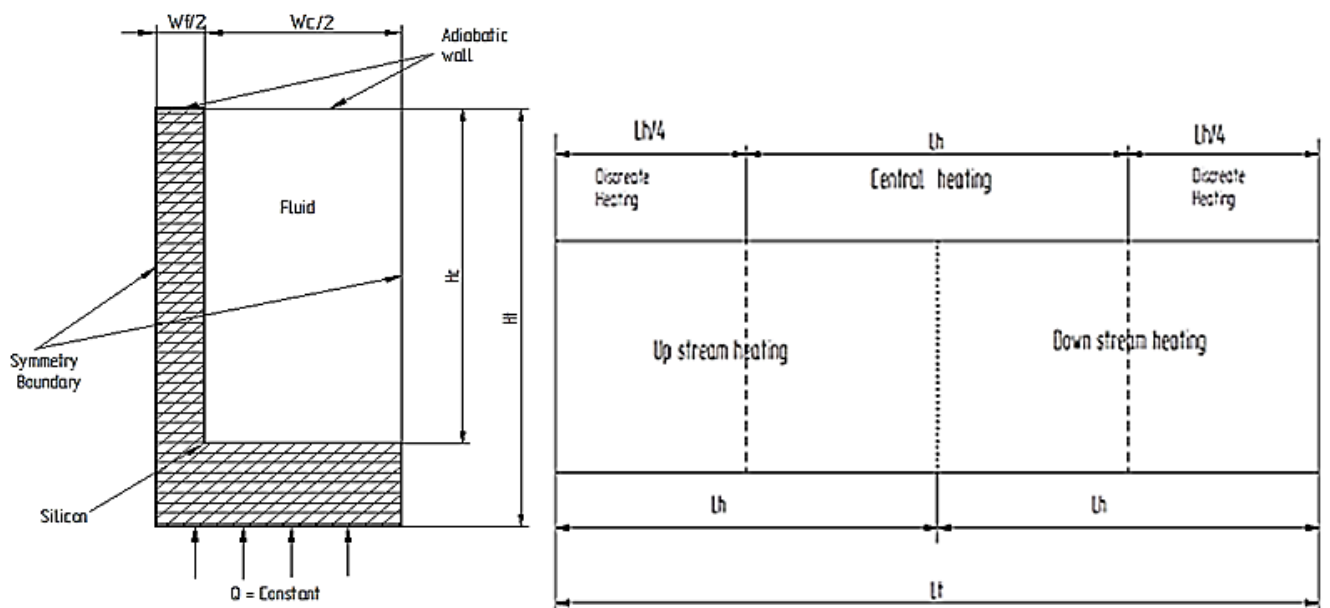

Fig-2.2: (a) Computational domain of Micro channel heat sink (b) Different heating position

Table2.1: Dimension of Micro channel heat sink

\begin{tabular}{|l|l|l|l|l|l|l|}
\hline Parameter & $\begin{array}{l}\text { Channel } \\
\text { width }(\mathrm{Wc})\end{array}$ & $\begin{array}{l}\text { Channel } \\
\text { height }(\mathrm{Hc})\end{array}$ & $\begin{array}{l}\text { Sink } \\
\text { width }(\mathrm{Ws})\end{array}$ & $\begin{array}{l}\text { Sink height } \\
(\mathrm{Hs})\end{array}$ & $\begin{array}{l}\text { Sink length } \\
(\mathrm{Lt})\end{array}$ & $\begin{array}{l}\text { Total Width } \\
(\mathrm{Wt})\end{array}$ \\
\hline Dimensions & $64 \mu \mathrm{m}$ & $280 \mu \mathrm{m}$ & $32 \mu \mathrm{m}$ & $489 \mu \mathrm{m}$ & $2 \mathrm{~cm}$ & $1.5 \mathrm{~cm}$ \\
\hline
\end{tabular}




\subsection{Mathematical Formulation and Governing} Equation

Water is used as coolant and heat sink is made from Silicon. The properties of the heat sink and the coolant are shown in Table 2.2.

Table 2.2: Properties of Coolant and heat sink

\begin{tabular}{|l|l|l|l|l|}
\hline & $\begin{array}{l}\rho \\
(\mathrm{Kg} / \mathrm{m} 3)\end{array}$ & $\begin{array}{l}\mathrm{Cp} \\
(\mathrm{J} / \mathrm{Kg}- \\
\mathrm{K})\end{array}$ & $\begin{array}{l}\mathrm{K} \\
(\mathrm{W} / \mathrm{m}- \\
\mathrm{K})\end{array}$ & $\mu(\mathrm{Kg} / \mathrm{m}-\mathrm{s})$ \\
\hline $\begin{array}{l}\text { Fluid } \\
\text { (water) }\end{array}$ & 998.2 & 4182 & 0.6 & 0.000463 \\
\hline $\begin{array}{l}\text { Heat Sink } \\
\text { (silicon) }\end{array}$ & 2329 & 710 & 148 & $---\cdot-\cdot-\cdot---$ \\
\hline
\end{tabular}

Numerical Analysis is performed under the following assumption.

i) Flow is steady, laminar and incompressible.

ii) All properties remain constant.

iii) Body forces and losses due to radiation are neglected.

Based on the above assumption, the following equation is solved to compute velocity and temperature distribution Continuity equation

$$
\nabla V=0----------(1)
$$

Momentum equation

$$
\rho(V \nabla V)=-\nabla P+\nabla(\mu \nabla V)
$$

Energy equation

$$
\rho C_{p}(V \nabla V)=K \nabla^{2} T--------(3)
$$

Governing equation for heat sink

For heat sink the governing equation is given by

$$
\nabla^{2} T=0--------(4)
$$

\subsection{Boundary Condition}

At entry, fluid velocity and temperature is imposed as inlet condition. The inlet velocity are computed with respect to Reynolds number $\operatorname{Re}=\rho \operatorname{sud}_{h} / \mu$, where $\mathrm{d}_{\mathrm{h}}$ is the hydraulic diameter, $\mathrm{dh}=d_{h}=4 A_{c} / P, \mathrm{u}=\mathrm{v}=0$ and $\mathrm{w}=\mathrm{w}_{\mathrm{in}}$. The temperature of the fluid at the entry ispresumed to be $\mathrm{T}_{\text {in }}=$ $293 \mathrm{~K}$; at the outlet of the channel, the flow ispresumed to be fully developed; and no slip boundary condition ispresumed at the solid boundaries. Heat flux boundary condition is imposed for the bottom surface of heat sink, adiabatic condition is assumed for the upper wall and symmetry condition is imposed for right wall andthe left wall. Thus, At the inlet a uniform velocity and atmospheric temperature is specified $\mathrm{U}=\mathrm{U}$ in, $\mathrm{T}=\mathrm{Tin}$, The upper surface is insulated and defined as $K \frac{\partial T}{\partial x}=0$ At $\mathrm{Z}=\mathrm{L},=0$.A uniform heat flux is applied to the bottom surfaceIn solids $\mathrm{U}=\mathrm{V}=\mathrm{W}=0$

For Symmetry wall $v=0, \frac{\partial w}{\partial z}=0, \frac{\partial v}{\partial y}=0, \frac{\partial u}{\partial x}=0$

\subsection{Numerical Solution}

The governing continuity, momentum and energy equations were solved using the Finite Volume Method. Convective terms were discretised using Second order upwind scheme and simplec algorithm was used for pressure-velocity coupling to obtain pressure field. Segregated solver was used to solve conservation scheme. The convergence criteria for continuity, momentum and energy equation was set to $10^{-6}$. The entire work was carried out using "FLUENT". A grid independence study was conducted for $\operatorname{Re}=50$ and upstream condition. it was observed that the outlet temperature of coolant for mesh size $10 * 25 * 100$ and $20 * 40 * 150$ were $309.5 \mathrm{~K}$ and $309.8 \mathrm{~K}$ respectively. Since change in temperature is very negligible computation domain with $10 * 25 * 100$ mesh size was considered for present work.

\section{RESULTS \& DISCUSSIONS}

\subsection{Validation Case}

Figure 3.1 shows the comparison between present computation and validation result for variation of temperature along the axial length for upstream heating, central heating and downstream heating for $\mathrm{Re}=214$ and heat flux $=34.6 \mathrm{~W} / \mathrm{cm}^{2}$. In case of upstream heating and central heating it is clearly seen that the temperature increases at the beginning of the micro channel reaches a maximum value at the centre and decreases at the end portion of the micro channel. The Maximum temperature in both the cases is close to $298 \mathrm{~K}$, the only difference is in case of a central heating the maximum temperature is away from the central portion of the micro channel. Where as in case of downstream heating, since the heat flux is applied in the end portion of the micro channel for the initial portion of the micro channel the temperature remains constant and increases towards the end portion to a value of $298 \mathrm{~K}$ as shown in figure 3.1. it is observed from the graph there is a close agreement between computed result and validated result.

\subsection{Friction Factor}

It is observed in fig 3.2 friction factor decreases with increase in velocity for all heating position of micro channel. At low flow velocity, resistance to flow is very less which increases the friction factor. As flow velocity increases, resistance to flow increases and decreases the friction factor. 
The friction factor is slightly less for downstream heating compared to other cases.
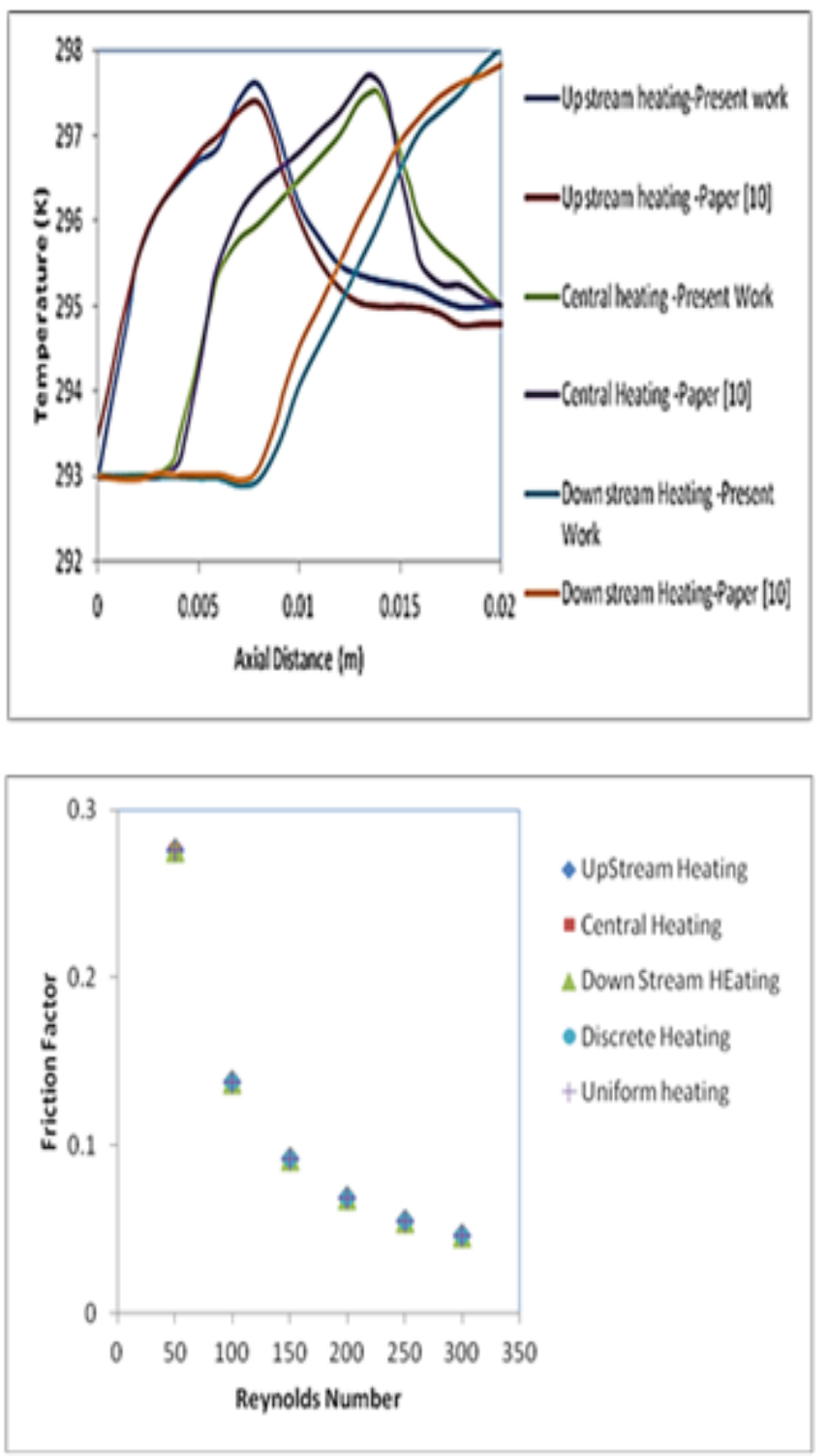

\subsection{Thermal Performance}

\subsubsection{Delta $T$}

Fig 3.3: shows the variation of delta $T\left(\mathrm{~T}_{\text {out }}-\mathrm{T}_{\text {in }}\right)$ for $50 \mathrm{~W} / \mathrm{cm} 2$ with Reynolds number for different heating position. For all the cases delta $\mathrm{T}$ decreases with increase in Reynolds number. At low flow velocity fluid flows at slower rate absorbing more amount of heat thereby bulk temperature of fluid at outlet increases due to diffusion heat transfer, whereas as flow velocity increases fluid travels at faster rate absorbing less amount of heat reducing the outlet temperature of fluid due to forced convection. In case of uniform heating the temperature of fluid along the channel increases gradually, hence delta $\mathrm{T}$ for uniform heating is approximately $35 \%$ more compared to other heating position. Similar trend is observed for $70 \mathrm{~W} / \mathrm{cm}^{2}$.

\subsubsection{Thermal Resistance}

The variation of thermal resistance with Reynolds number is presented for all heating position as shown in figure 3.5 (a) and (b). $\quad$ Rth $=T_{\max }-T_{\text {in }} / q$. For all heating position thermal resistance decreases with increase in Reynolds number. From the graph it is evident thermal resistance is lowest for discrete heating followed by central, upstream, downstream and uniform heating. Thermal resistance decreases by $30 \%$ for discrete heating compared to uniform heating, whereas for remaining heating position decrease in thermal resistance is less than 5\%.Due to axial conduction heat transfer, the maximum surface temperature is lower for discrete heating compared to other heating position resulting in decrease in thermal resistance.
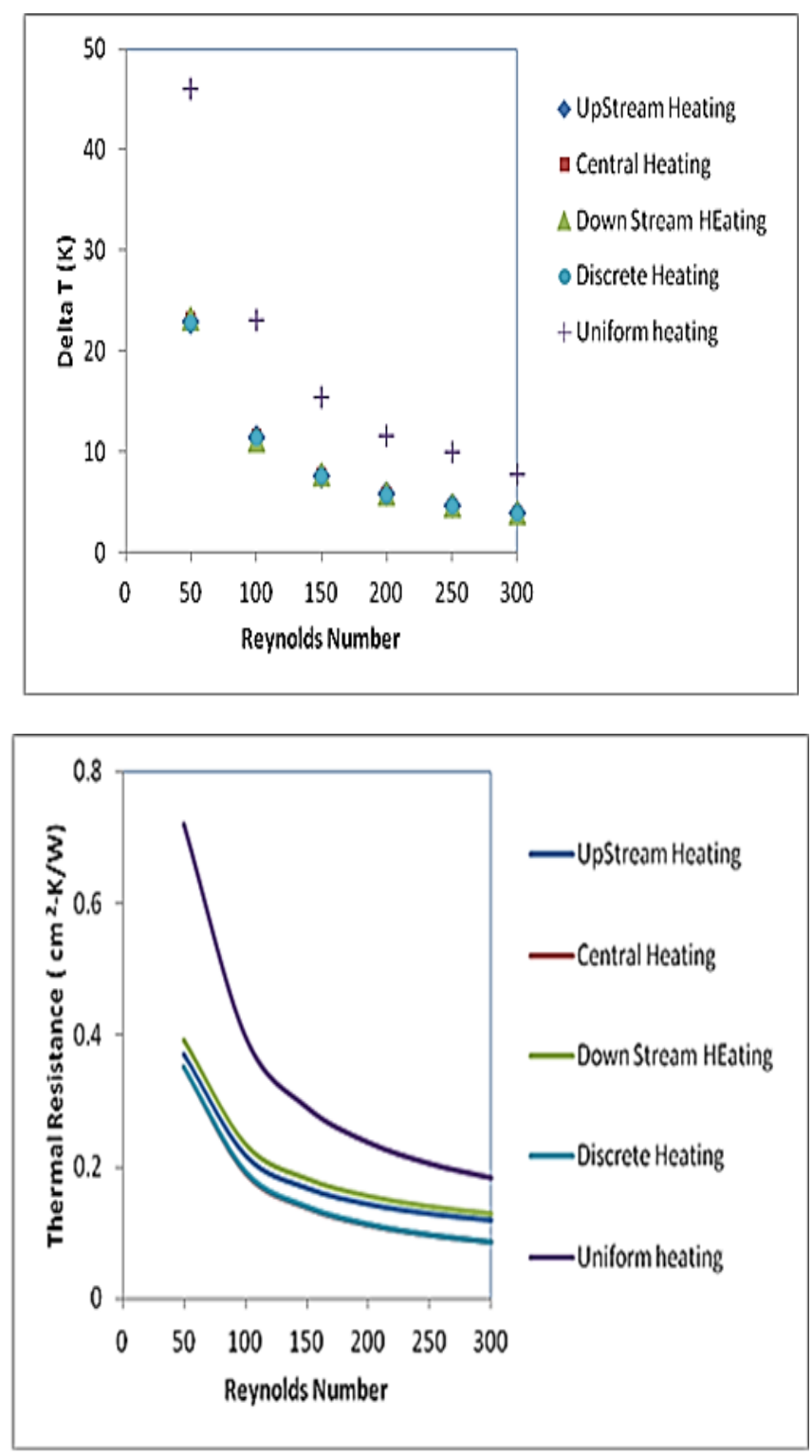

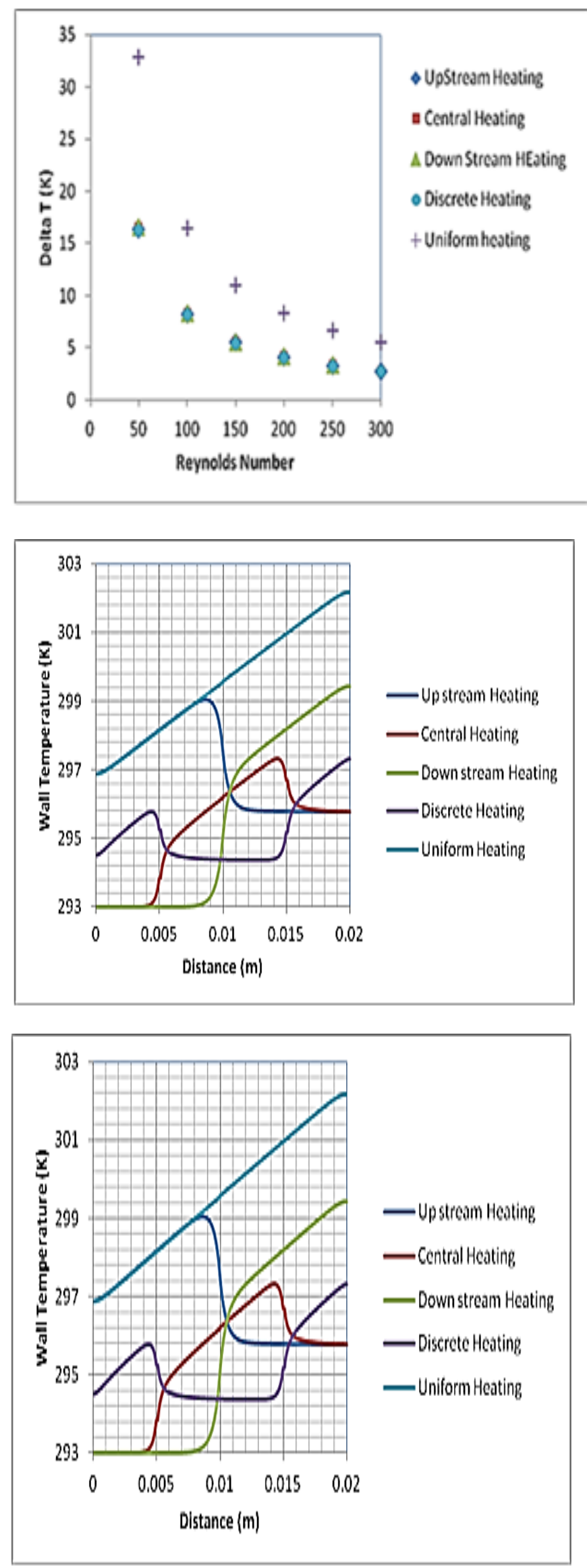

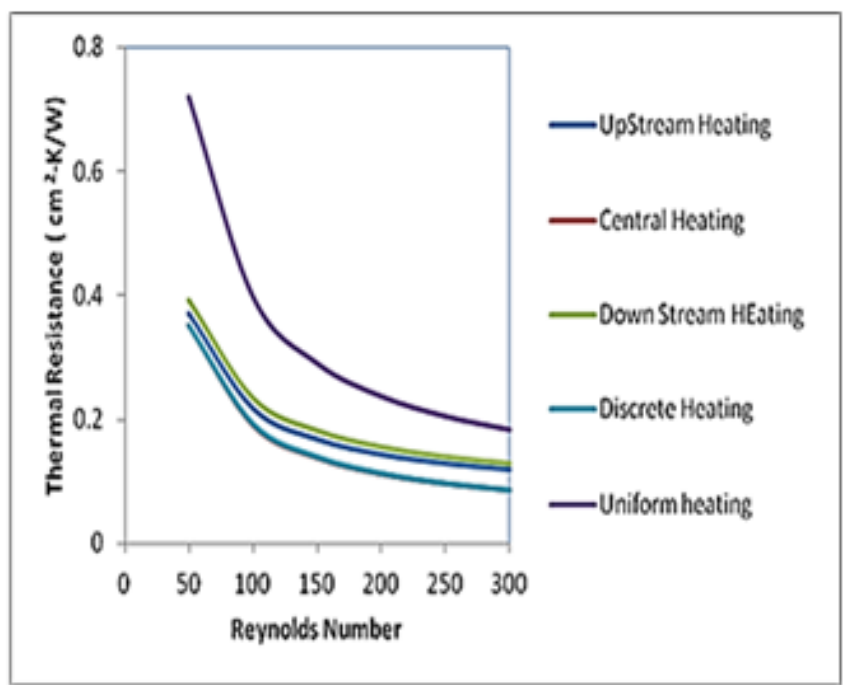

\subsubsection{Wall Temperature}

Fig 3.6 (a) and (b) Shows the variation of wall temperature along axial length of micro channel for different Reynolds number.The following conclusion were drawn from figure 3.6. In case of uniform heating wall temperature increases linearly along the length of channel for all values of Reynolds number. In case of upstream heating, the wall temperature at channel entry is slightly more than inlet temperature of fluid, increases till midway and remains constant due to axial conduction heat transfer along latter half of channel. For $\mathrm{Re}=50$ the peak temperature is obtained at $0.94 \mathrm{z}$ and decreases to $0.85 \mathrm{Z}$ for $\mathrm{Re}=300$. This implies convective heat transfer is dominant with increase in Reynolds number. In case of central heating, there is a sudden increase in wall temperature at centre of micro channel and remain constant thereafter. In case of discrete heating, there is a slight rise in wall temperature at entry and exit of channel, whereas remain constant in between the reason is convective heat transfer is more dominant at inlet and exit compared to axial conduction heat transfer at centre of channel, hence average surface temperature is less compared to other heating position.

\subsubsection{Heat Transfer Co Efficient}

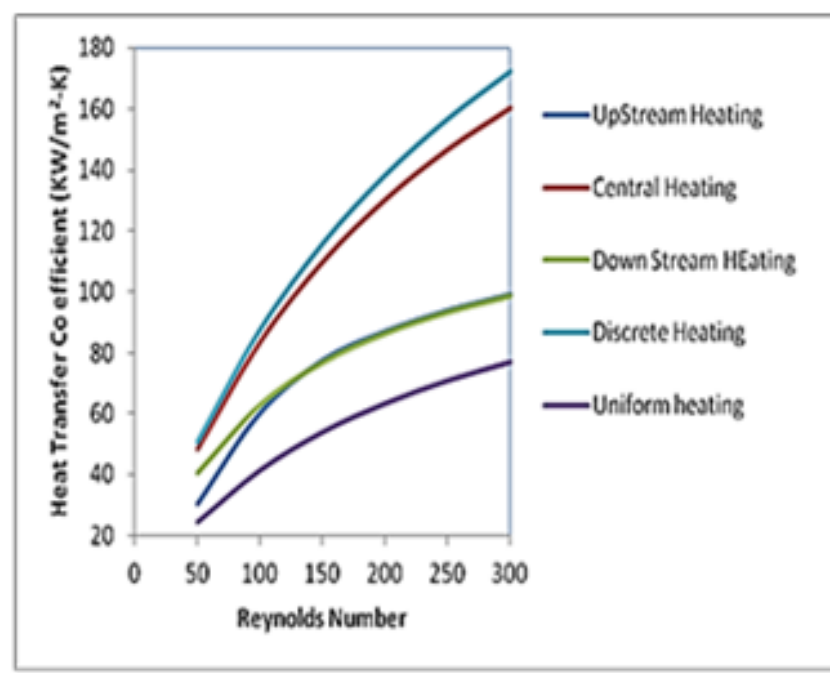




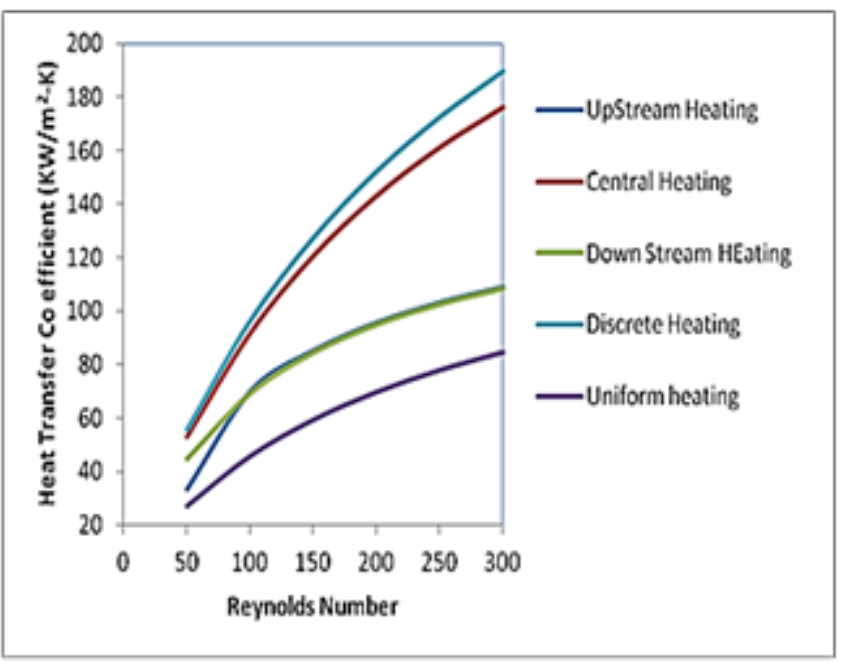

For all heating position heat transfer co efficient increases with increase in Reynolds number.It is observed HTC is maximum for downstream heating and increases approximately by $40 \%$ in comparison with uniform heating for different heat flux as shown in figure 3.7

\section{CONCLUSION}

Based on the numerical investigation the following conclusions were drawn

1. It was observed hydrodynamic and thermal behavior of micro channel are largely influenced by heating position and heat flux

2. Friction factor decreases with Reynolds number and remain same for different heating position

3. Bulk Temperature of coolant decreases with Reynolds number, is maximum for uniform heating whereas remain almost constant for other heating position

4. Thermal Resistance is minimum for discrete heating and maximum for uniform heating

5. Performance of micro channel with discrete heating is considered to be superior with high heat transfer coefficient compared to other heating position

6. Variation of wall temperature for different heating position is discussed

\section{REFERENCES}

[1] D.B. Tuckerman, R.F.W. Pease, " High-performance heat sinking for VLSI", IEEE Electron. Device Lett., vol. EDL-2, 1981, pp. 126-129.

[2] Weilin Qu, Issam Mudawar, "Experimental and numerical study of pressure drop and heat transfer in a single-phase micro-channel heat sink". International Journal of Heat and Mass Transfer, vol.45, 2002,pp.2549-2565.

[3] Weilin Qu, Issam Mudawar, "Analysis of threedimensional heat transfer in micro-channel heat sinks". International Journal of Heat and Mass Transfer, vol 45 (2002) 3973-3985.

[4] G. Hetsroni , A. Mosyak, E. Pogrebnyak, L.P. Yarin, "Heat transfer in micro-channels: Comparison of experiments with theory and numerical results",
International Journal of Heat and Mass Transfer,vol. 48.pp. 5580-5601,2005.

[5] Roy W. Knight, Donald J. Hall, John S. Goodling, and Richard C. Jaeger, "Optimal Thermal Design of Forced Convection Heat Sinks-Analytical", Fellow Mechanical Engineering Department, Auburn University, Auburn, AL 36849.

[6] Gamrat, G., Marinet, M. F., and Asendrych, D., 2005, "Conduction and entrance effects on laminar liquid flow and heat transfer in rectangular microchannels," Int. J. Heat Mass Trans., 48(14), pp. 2943-2954.

[7] Zhao, C.Y. and Lu, T.J. (2002), "Analysis of microchannel heat sinks for electronics cooling", International Journal of Heat and Mass Transfer, Vol. 45, pp. 4857-69.

[8] W.A. Khan, J.R. Culham, "Optimization of pin-pin heat sinks using entropy generation minimization", IEEE Trans. Compon. Packag. Technol. Vol.28,pp.247-254,2005.

[9] R.Kalaivanan, R.Rathnasamy, "Experimental Investigation of Forced Convective Heat Transfer in Rectangular Micro-channels", Jordan Journal of Mechanical and Industrial Engineering,vol.5 Number 5 (ISSN 1995-6665)

[10] Dorin Lelea, "The heat transfer and fluid flow of a partially heated microchannel heat sink,International Communications in Heat and Mass Transfer,vol. 36,pp. 794-798,2009

[11] J H ryu, D H Choi, S J Kim, numerical optimization of thermal performance of micro-channel heat sinks, Journal of Heat Mass Transfer 2001

[12] P.S. Lee, S.V. Garimella, D. Liu, "Investigation of heat transfer in rectangular micro-channels", International Journal of Heat Mass Transfer, vol. $48,1688-1704,2005$

[13] H.S. Kou, J.J. Lee, C.W. Chen, "Optimum thermal performance of micro-channel heat sink by adjusting channel width and height", International Communications in Heat and Mass Transfer vol.35,pp.577-582,2008.

[14] Reiyu Chein , Janghwa Chen, "Numerical study of the inlet/outlet arrangement effect on microchannel heat sink performance", International Journal of Thermal Sciences,vol.48,pp. 1627-1638,2009.

[15] J. Li a , G.P. Peterson a, P. Cheng b "Threedimensional analysis of heat transfer in a micro-heat sink with single phase flow", International Journal of Heat and Mass Transfer 47 (2004) 4215-4231. 